\title{
When it can be good to feel bad and bad to feel good: Exploring asymmetries in workplace emotional outcomes
}

\section{Dirk Lindebaum}

University of Liverpool, UK

\section{Peter J Jordan}

Griffith University, Australia

\begin{abstract}
Within the field of Management and Organizational Studies, we have noted a tendency for researchers to explore symmetrical relationships between so-called positive discrete emotions or emotion-infused concepts and positive outcomes, and negative emotions or emotion-infused concepts and negative outcomes, respectively. In this Special Issue, we seek to problematize this assumption (without aiming to entirely discard it) by creating space for researchers to study what we term asymmetrical relationships. In particular, we explore the topic of when it can be good to feel bad and bad to feel good. The articles presented in this forum demonstrate both theoretically and empirically that appreciating these asymmetrical relationships holds considerable promise for enhanced understanding of a range of management and organizational phenomena, ranging from leadership and followership to emotional labor and dirty work. These unique theoretical and empirical insights have important relevance for organizational practice.
\end{abstract}

\section{Keywords}

affect, context, discrete emotions, problematization, work outcomes

\section{Corresponding author:}

Dirk Lindebaum, Management School, University of Liverpool, Chatham Street, Liverpool L69 7ZH, UK.

Email: d.lindebaum@liverpool.ac.uk 
The study of emotions or emotion-infused concepts in the workplace continues to fan the imagination of many Management and Organization Studies (MOS) scholars (for authoritave reviews, see Ashkanasy, 2003; Barsade and Gibson, 2007; Barsade et al., 2003; Elfenbein, 2007; Fineman, 2008). Indeed, Human Relations was at the forefront of this stream of research when it published Ashforth and Humphrey's (1995) thoughtprovoking article, which sparked considerable interest around the role of emotions in organizations. Other eminent theoretical and empirical contributions followed, which significantly advanced our understanding of discrete emotions or emotion-infused concepts in terms of their antecedents (Fisher, 2010; Lazarus, 1999), underlying processes (Gross, 1998; Lawrence et al., 2011) and consequences across levels of analysis (Fisher, 2010; Taris and Schreurs, 2009; Troth et al., 2012). This research is underpinned by a number of prominent theoretical contributions in the field, including - but not restricted to - Hochschild's (1983) framework of Emotional Labor, Mumby and Putnam's (1992) Theory of Bounded Emotionality, Weiss and Cropanzano's (1996) Affective Events Theory, and Ashkanasy's (2003) comprehensive multi-level framework for emotions in organizations. In preparing this Special Issue, our focus was to contribute to this significant body of work by exploring emotions from a different perspective, which is commensurate with the aim of this journal to foster a better understanding of social relationships in and around work (Edwards, 2011).

This different perspective is captured in the title of this Special Issue (i.e. When it can be good to feel bad, and bad to feel good: Exploring asymmetries in workplace emotional outcomes), and reflects our interest in examining particular consequences of discrete emotions or emotion-infused concepts at work. In reviewing the significant number of studies on emotions at work, we observed the emergence of a symmetrical assumption among MOS scholars and practitioners, whereby so-called positive discrete emotions or emotioninfused concepts yield positive outcomes, whereas negative discrete emotions or emotioninfused concepts are associated with negative outcomes. In this Special Issue, we encouraged scholars to problematize (i.e. thinking differently about what we already know in MOS research, see Alvesson and Sandberg, 2011) the symmetrical relationships discussed above and to re-conceptualize them into asymmetrical ones in order to advance our understanding of when it can be good to feel bad and bad to feel good at work. Looking at our call for papers, we specifically stated several broader objectives. These are: (i) to challenge researchers to reconsider how we conceptualize the link between discrete emotions and emotion-infused concepts and particular outcomes at work; (ii) to elicit individual processes and meanings attached to when it can be good to feel bad and bad to feel good at work; (iii) to generate theory that provides alternative insights on the use of emotions at work and how certain emotion-infused concepts influence outcomes at work; and to (iv) to encourage empirical investigations that puts this theorizing to the test, and leads to improved organizational practices. In addition, we asked explicitly what factors (e.g. context, individual differences or display rules) influence the development of symmetrical or asymmetrical relationships between emotions/concepts and their outcomes?

\section{The dominance of symmetrical assumptions}

The genesis of this Special Issue lies in the dominance of symmetrical assumptions in the field as hinted at earlier. For example, Fredrickson (2003) suggests that nurturing positive 
emotions may aid organizations in preventing stagnation, while enhancing employees' well-being and health. In a similar vein, the concepts of emotional intelligence or compassion are firmly embedded in the positive psychology literature (Gable and Haidt, 2005; Salovey et al., 2002). In this regard, research shows that emotional intelligence is consistently associated with positive interpersonal relationships, higher levels of life satisfaction, better well-being and mental health (Hertel et al., 2009; Martins et al., 2010; Mayer et al., 2008), while compassion induces care-taking behaviors, especially when increased perceived self-other similarity is present (Oveis et al., 2010). In contrast, studies on negative affectivity highlight its negative consequences, such as greater levels of work-related depression (Heinisch and Jex, 1997), and outcomes associated with negative mood, including a lack of control in maintaining a professional demeanor (Beal et al., 2006). And of course, there is evidence to suggest that anger is associated with reduced inspirational leadership capability (i.e. ineffective leadership, see Waldman et al., 2011) or intent to harm the target (Berkowitz and Harmon-Jones, 2004).

\section{Why do symmetrical assumptions appeal?}

The examples provided underscore the dominant symmetry of positive emotions leading to positive outcomes and negative emotions leading to negative outcomes. But merely noting that this symmetrical assumption exists does not go far enough. It is of intrinsic significance to ask and understand why this general tendency emerged in the first place? Although we cannot offer an absolute answer to this question, one factor that is likely to play a role is the contemporary zeitgeist of how researchers conceive of the expression of emotions and their outcomes in the workplace. Relevant here are 'emotionologies', defined by Stearns and Stearns (1985) as 'the attitudes or standards that a society ... maintains toward basic emotions and their appropriate expression; ways that institutions reflect and encourage these attitudes in human conduct' (p. 813). ${ }^{1}$

Linking the tendency to focus upon symmetrical assumptions with emotionologies indicates the possibility that the underlying processes of psychological/management concepts are conflated with their outcomes. To provide an example, consider the construct of emotional intelligence (conceptualized as a human ability, see Mayer et al., 2008). The widely cited definition of emotional intelligence suggests that it concerns 'the ability to perceive accurately, appraise, and express emotion; the ability to access and/or generate feelings when they facilitate thought; the ability to understand emotion and emotional knowledge; and the ability to regulate emotions to promote emotional and intellectual growth' (Mayer and Salovey, 1997: 10, emphasis added). ${ }^{2}$ What this definition indicates is that mastery across the four abilities leads to emotional and intellectual growth. Yet, as Suddaby (2010) cautions, when scholars define a given construct, the processes that underlie that construct must not be conflated with its outcomes. If these are not distinguished, situations are created where our own value-judgments predetermine that nature of the outcome (Lindebaum and Jordan, 2012). Reverting back to the example of emotional intelligence, we need to be cautious about how we use valuedriven construct definitions. Especially in the context of emotion research, doing so is problematic since the subjective experiences of individuals do not always map onto these outcomes (see Fineman, 2004; for a detailed treatment of this argument). In other words, positive emotions are not always linked to positive outcomes (e.g. hubristic pride) and 
negative emotions are not always linked to negative outcomes (e.g. anger motivating an individual to respond to a social justice problem, see Lindebaum and Geddes, 2014).

\section{Challenging the dominant assumption}

Given this state of affairs, we are concerned that this symmetrical zeitgeist can constrain wider social inquiries by privileging ways of theorizing and management practice that do not always reflect organizational realities (Lindebaum and Jordan, 2012). In consequence, we argue that the symmetrical approach can distract researchers from problematizing existing knowledge to see more 'really interesting and innovative research' being published (Ashkanasy, 2011: 819).

If we apply the notion of problematization to our Special Issue, it prompts us to ponder whether it is worthwhile to appreciate the possibility of asymmetrical relationships as well? Exploring this question, we observed new and interesting outcomes of research emerging when this basic symmetry is not supported. In particular, we found recent research suggesting that sadness motivates the positive behavior of building social connections, but only if sadness is motivated by social loss rather than loss of status (Gray et al., 2011). In a similar vein, a small body of studies suggests that anger is not always related to negative outcomes at work. For instance, Lindebaum and Fielden (2011) show that anger is related to perceived leader effectiveness in the context of construction, while Geddes and Stickney (2011) demonstrate that co-workers and managers can react supportively (rather than punitively) to angry employees, leading to favorable changes that improved the situation in the context of an aerospace and a mechanical services firm. Likewise, compassion, far from yielding only positive outcomes at work (such as sustained organizational effectiveness, see Kanov et al., 2004), can have negative consequences for individuals at work. Specifically, too much compassion can lead to what has been termed 'compassion fatigue' (Figley, 1995). In the context of health care providers who care for chronically ill children, this has been shown to induce stress in affected individuals (Meadors and Lamson, 2008). Lastly, a small body of research suggests that individuals high in emotional intelligence achieved lower negotiation outcomes in negotiation dyads compared with their lower emotional intelligence counterparts (Foo et al., 2004), or may develop higher deviance tendencies in emotionally standardizing environments (Lindebaum, 2012; see also, Winkel et al., 2011). While some have suggested that the role of context in influencing findings in MOS may be overstated (Ashkanasy, 2007), findings such as those stated above prompt us to concur with Johns (2006: 389), who notes that 'context is likely responsible for one of the most vexing problems in the field: study-to-study variation in research findings'. Our conclusion after examining the literature is that the existence of asymmetrical relationships may be closely - but not exclusively - tied to the underlying context of a study.

Reviewing studies that report asymmetrical findings prompted us to revisit social functional accounts of emotions (Keltner and Haidt, 1999; Sell et al., 2009). Seen in this light, 'functionality' refers to consequences of goal directed behaviors (e.g. redressing injustice is a function and consequence of anger, see Keltner and Haidt, 1999). As Frijda (2007) claims, from a functionalist perspective, the notion of a truly negative emotion is more myth than reality, adding that all emotions are potentially adaptive states of action 
readiness. Therefore, we agree with Fitness (2008: 61), who notes that negative emotions 'may or may not have destructive consequences'. For instance, while sadness has been labeled as a negative emotion (Tiedens, 2001), it constitutes a judgment of loss and can offer an opportunity for openness and intimacy, especially when the loss is shared with others (Solomon, 1993). This is consistent with the aforementioned study that sadness motivates the positive behavior of building social connections (Gray et al., 2011). Emotional support thus obtained can be vital en-route to recovery from a loss that one has experienced. Likewise, anger is neither inherently 'good' nor 'bad', or universally 'positive' or 'negative'. Instead, the consequences depend upon a combination of the circumstances that elicited the anger response, the individuals involved, the type of anger displayed and how that anger was directed (Solomon, 1993). In terms of the genesis of anger, Lindebaum and Geddes (2014) highlight the significant social function of anger if elicited by perceptions of injustice and unfairness or violations of individuals' dignity, where these perceptions induce approach behaviors to address the wrongdoing at the social level. It is for this reason that we argue elsewhere (Lindebaum and Jordan, 2012) that it is probably more helpful if descriptions, such as 'positive' or 'negative' emotions (and, by extension, emotion-infused concepts), are replaced with a focus upon the utility (or functionality) of a particular emotion (or emotion-infused concepts) as it relates to a particular context or situation. More specifically, we note that 'discrete emotions can be interpreted differently across contexts', so it is 'pertinent to ask "of utility for whom within a specific context"?' (Lindebaum and Jordan, 2012: 1029).

In consequence, we argue that the juxtaposition of contemporary emotionologies and social functional accounts of emotions suggests that the former potentially have overridden the latter. In other words, social conventions that govern the public expressions of emotions often are valued over the actual utility of that emotion. Consequently, workers are often told to be 'positive', or to suppress 'negative' emotions consistent with organizational expectations (Lindebaum, 2012). This is despite overwhelming evidence that emotions have sense-making utility and can help to explain individual perceptions of a given situation or context - an important individual and social function (e.g. Keltner and Haidt, 1999).

We recognize, however, that context may not be the only explanation that can account for the asymmetrical effects that lie at the heart of this Special Issue. As a number of articles presented in this forum indicate, asymmetrical relationships can also be influenced by the presence of a moderator variable. Indeed, in this collection asymmetrical relationships are encouraged by personality variables, by emotion, by abilities and by motivations. We believe there is an interesting opportunity for future research to unpack in more detail the mutually exclusive and inclusive influence of context and moderator variables that might (or might not) exist independent of that context.

\section{The current Special Issue}

After a rigorous review process, five articles with the strongest fit to the Special Issue were selected for publication. Unfortunately, this implied that one high-quality article that was accepted for the Special Issue by Genevieve Johnson and Shane Connolly (Human Relations 19 June 2014, 0018726714532856 [http://hum.sagepub.com/content/early/201 
4/06/19/0018726714532856.abstract]) had to be transferred to a regular issue. The articles selected (individually and collectively) speak to the aim and objectives for the Special Issue by providing different aspects of this phenomenon, using a variety of ontological, epistemological and methodological approaches.

Despite this variety, three informative themes can be distilled from the accepted articles, and these themes are largely represented (however split) in the title of our Special Issue. To briefly foreshadow, the studies by Chi and Ho, Hadley, as well as Mitchell and her colleagues reflect the first theme (i.e. when it can be good to feel bad), while the study by McMurray and Ward speaks to the second theme (i.e. when it can be bad to feel good). We note that the preponderance of the first theme reflects the findings of Hadley's study suggesting that negative events at work influence more often positive outcomes than negative ones. Finally, within the third theme, Van Kleef offers an integrated theoretical model that allows both themes 1 and 2 to co-exist (i.e. when it can be good to feel bad and bad to feel good) - given the presence of corresponding moderators - including the ones reflecting underlying context.

\section{Theme I: When it can be good to feel bad}

The article by Nai-Wen Chi and Ta-Rui Ho provides a rigorous and methodologically sound quantitative study (i.e. multi-source and multi-phase surveys) that provides a good test of our central theme of asymmetries. Using Van Kleef's (2009) Emotions as Social Information (EASI) model, Chi and Ho examine emotional asymmetries in the context of leader and follower relationships. They specifically focus on follower performance outcomes when a leader displays negative emotions (rated by their follower). This immediately differentiates this study from prior research where leaders are asked to assess their own emotional reactions. Followers' individual performance was rated by managers. Initially, Chi and Ho use this rigorous method to examine the results of other studies (e.g. Lindebaum and Fielden, 2011). They extend this research to show that this asymmetrical relationship is moderated by personality variables. For example, their study demonstrates that follower conscientiousness has a major impact on whether negative emotional expressions lead to better or worse outcomes. A similar result was found in relation to follower agreeableness, with followers who were high in agreeableness performing better in response to a negative emotional expression from the leader than those employees with low agreeableness. In summary, the Chi and Ho article strengthens our understanding of asymmetrical outcomes from negative emotional expressions and the importance of considering individual difference variables in moderating this process. By introducing moderating variables into their research, the authors specifically address the objective of the Special Issue to re-conceptualize the link between discrete emotions or emotion-infused concepts and particular outcomes at work both theoretically and empirically.

The second article in this theme by Constance Hadley reports on 71 discrete events gathered by conducting semi-structured interviews with 34 US professionals. Participants discussed the outcomes of both emotionally positive events and emotionally negative events. Working within the framework of emotional regulation (Gross, 1998), Hadley explores how specific emotional regulation strategies are used in organizations and the outcomes of using these strategies. Interestingly, Hadley quantifies the incidence of 
symmetrical and asymmetrical outcomes following the emotional event. Our analysis of her data reveals that, while negative events resulted in negative outcomes in approximately 30 percent of cases (a symmetrical outcome), in approximately 70 percent of cases they resulted in a positive outcome (an asymmetrical outcome). This finding firmly underlines the significance of these asymmetrical assumptions for organizational practice (i.e. that it can be good to feel bad at work), a view that flies in the face of some proponents of positive psychology, who encourage workers to minimize negative emotional displays at work (Luthans et al., 2004). On the other hand, when examining the outcomes of positive emotional events, a stark result was found. Of the 19 positive interactions workers discussed, approximately 94 percent were categorized as resulting in a symmetrical outcome (positive to positive), while respondents only reported one (approximately 6\%) had an asymmetrical outcome (positive to negative). Significantly, Hadley notes during her analysis that there were times when respondents identified conflicting emotions within the one event (sadness mixed with hope and happiness mixed with worry). In her article, Hadley makes a significant contribution to this Special Issue by using her data to outline the dynamic within-person variance that occurs in dealing with emotions at work. Hadley also provides an original theoretical framework that will be useful to other researchers wishing to extend Hadley's research. In so doing, her study speaks, inter alia, to our objective to generate theory that provides alternative insights on the use of emotions at work and how they influence outcomes at work.

Also addressing this theme is the article of Mitchell and her colleagues, who examine asymmetries in the context of teams. They offer a conceptual model (and an empirical test using a sample of 75 teams) on the factors enhancing our understanding of the dynamics that guide inter-professional teams towards the achievement of valued outcomes. Observing that inter-professional teams do not, of necessity, perform effectively, Mitchell et al. focus on the role of negative affect in producing asymmetrical outcomes.

Similar to the article by Chi and Ho, Mitchell et al. use the context of leadership to examine these relationships. In the model developed, negative affect acts as a moderator of the mediated relationship between transformational leadership and team effectiveness through inter-professional motivation and openness to diversity. Specifically, they found that inter-professional motivation is more positively related to team effectiveness when negative affective tone is high rather than low. The Mitchell et al. study shows that this is owing to the role of negative affective tone being a source of differentiation and dissatisfaction that encourages critical discussion and delays premature consensus in the presence of transformational leadership. This study shows that the suppression of negative affective tone can lead to detrimental outcomes, while providing an enhanced understanding of the underlying mechanisms for teams in this research area.

\section{Theme 2: When it can be bad to feel good}

McMurray and Ward focus on asymmetries that emerge as a result of emotional labor (see also Vincent, 2011) in the context of a UK charitable organization devoted to providing support for individuals in emotional distress. In their article, McMurray and Ward challenge Hughes's (1962) tripartite classification of dirty work in terms of physical, social and moral taints. They argue that this theory may require extension vis-a-vis a 
changing occupational landscape over the last decades and offer a novel conceptual definition of emotional dirt from a sociological perspective. Central to their findings is the portrayal of workers who deal with isolated, upset, abusive or suicidal individuals as organizational agents who contain society's emotional dirt. In particular, the authors highlight the leakage that occurs between work contexts and social contexts by noting the negative social consequences that can arise in response to the emotional labor performed by these workers, when, for instance, at social gatherings people fear that they 'might catch' the taint that they themselves attribute to the work of help line operators. McMurray and Ward juxtapose these potential negative social consequences with the intrinsically rewarding individual experience gained in dealing with the challenging work of others' negative emotions. Therefore, their study speaks to our objective to elicit individual processes and meanings attached to when it can be good to feel bad and bad to feel good at work.

\section{Theme 3: When it can be good to feel bad and bad to feel good}

One of the key objectives we sought to address in this Special Issue was an invitation to re-conceptualize the link between discrete emotion and emotion-infused concepts with a view to generate novel theory. The final article in our Special Issue by Van Kleef develops a theoretical framework that speaks to this objective and offers an alternative theoretical framework (including testable propositions) for better understanding the interpersonal (both symmetrical and asymmetrical) effects of happiness and anger using examples from the domain of negotiation and leadership studies. Van Kleef's interest lies in the question of when and how the display of happiness versus anger yields positive or negative outcomes for the expresser, even though the effects for the expresser are generated through the interpersonal reactions of the perceivers. His framework constitutes an extension of his own previous work on the EASI theory (Van Kleef, 2009). Unlike other theories (e.g. appraisal theories), this theory uniquely appreciates the organizational and social consequences of emotional expressions. Van Kleef extends our understanding of this phenomenon by arguing that whether the effects of anger or happiness expression are asymmetrical or symmetrical depends upon whether the perceiver has a stronger propensity toward affective reactions (i.e. a symmetrical effect influenced by violations of perceived appropriateness) or inference drawing (i.e. an asymmetrical effect influenced by higher perceiver ability and motivation to process information). In summary, Van Kleef's theoretical model proffers an intriguing 'roadmap' for future research on the inter-personal consequences of expressing discrete emotions.

\section{Synthesizing articles in terms of the general tendency}

Having introduced the articles of this Special Issue, it is instructive to briefly synthesize them with regard to the presence of the general tendency of asymmetrical outcomes. We have speculated earlier that contemporary emotionologies encourage research involving symmetrical assumptions, while social functional accounts of emotions allow us to broaden our research to consider both symmetrical and asymmetrical effects. 
As highlighted before, we do not know yet whether empirical evidence will eventually support our conjecture about the interesting nature of asymmetrical relationships. However, we follow Popper (2004) in suggesting that this conjecture (with its subsequent confirmation or refutation) is of intrinsic importance to the progress of scientific knowledge per se. At the same time, in suggesting this, we do not want to 'throw the baby out with the bathwater'. There are some contributions in this Special Issue where emotionologies seemingly play an important part. For instance, Van Kleef's model includes the appropriateness of the emotional expression as one variable moderating the relationship between the expression of an emotion by an individual and how that expression influences outcomes in the perceiver. The appropriateness of emotional expression is partly governed by what Diefendorff and Greguras (2009) define as display rules, that is, 'cognitive structures pertaining to social conventions about the appropriateness of emotional displays in social situations' (p. 881), which represent 'dynamic, contextsensitive beliefs about how one should express emotions at work' (p. 896). The emphasis on social conventions ties in closely with normative expectations as far as emotional expressions are concerned, and violations of the latter oftentimes prompt individuals to conclude that the expression was inappropriate (see Van Kleef, this issue). In light of how emotionologies are defined, it is plausible to suggest that they play some role in prompting individuals to conclude that normative expectations have been violated.

Another candidate to consider in terms of the importance of emotionologies is the study by McMurray and Ward on the nature of emotional dirt, which reflects society's attitudes toward help-line workers engaged in supporting individuals who - for a variety of reasons - have difficulty in obtaining support for emotionally challenging life situations elsewhere. These help-line workers are, according to McMurray and Ward, those organizational agents whose task it is to contain society's emotional dirt. We can see that this speaks to the emphasis on how society reflects and encourages particular attitudes in the way individuals conduct themselves in society (Stearns and Stearns, 1985). In particular, the article by McMurray and Ward demonstrates the limited contribution that a narrow focus on specific variables may produce in research. Indeed, the focus upon a broader set of outcome variables allows McMurray and Ward to reveal asymmetries that would not be evident to researchers only focusing on job satisfaction or commitment.

In terms of organizational practice, studies presented in this forum suggest that individuals can experience considerable within-person variance at work in terms of negative and positive emotions in one day (see also Ouweneel et al., 2012; Xanthopoulou et al., 2012). Based upon this, it is probably too simplistic to expect everyone to be positive at work in order to enhance individual or team outcomes. Any intervention designed to instill this sense of positivity to attain these ends runs the risk of ignoring important emotions that could drive (rather than stifle) performance. After all, the dire consequences of viewing ineffective management practice as effective (e.g. for recruitment of developmental purposes) are well documented (McDaniel et al., 2006). Therefore, from the perspective of organizational practice, this Special Issue has shown that there are many examples where the acceptance of this variation in emotion (and particularly the acceptance of negative emotion at work) can result in good outcomes for the individual and the organization. 


\section{Further theoretical and practical reflections on undertaking this Special Issue}

There is a significant Type II error in publishing. Good manuscripts sometimes do not make the cut as more competitive articles are accepted. For this reason, we feel it is important to acknowledge what we learned from those manuscripts that were not accepted as well. Among the manuscripts submitted, we observed manuscripts emerging from two broad categories. There were those authors for whom the possibility of asymmetries in emotional outcomes seemed to spark some new ideas, while for other authors this framework provided a home for some data that had been collected and of which they could only now make sense.

At this point we wish to record our gratitude to the authors who have submitted their manuscripts to our Special Issue. We found that there were a number of manuscripts (even some that were rejected) that contributed to advancing our thinking on this broad topic. In particular, we found that our initial criticism of the simplicity of symmetrical assumption was developed at face value independent of time and space. We soon came to realize that an excessive focus on asymmetrical assumptions is likely to create the same problems as an excessive focus on symmetrical assumptions. Some authors, in discussing potential papers, noted that relationships might first appear as symmetrical, but over time may turn asymmetrical. This, to us, suggests the importance of tracking within-person variance in these types of relationships (Fisher and To, 2012; Ouweneel et al., 2012; Radcliffe and Cassell, 2013). The other possibility that was raised by our authors was the potential for curvilinear relationships (see Pierce and Aguinis, 2013). This has already been raised as a possibility in the field of emotional intelligence (Jordan et al., 2010; Lindebaum, 2012) and has the potential to be explored further in relation to asymmetries. Without a doubt, we as Guest Editors are indebted to all those authors who submitted to the Special Issue for extending our thinking on this topic.

\section{Conclusion}

Special Issues have been said not to be special anymore (Priem, 2006). Leaders in the field have raised concern about the sheer proportion of pages devoted to Special Issues and the contribution of these to the proliferation of fads in terms of management topics (McKinley, 2007; Priem, 2006). We do not share this pessimistic view. For us, the enduring appeal of this Special Issue is to invite researchers to capture a phenomenon that both researchers and practitioners observe in practice quite often, but one that has attracted only minor traction in mainstream journals. We trust this Special Issue goes beyond any one specific topic and discipline and prompts researchers to examine a wide array of research streams that, despite their varied character, still have an identical underlying nature. That is, it can be good to feel bad and bad to feel good in terms of outcomes at work. In this respect, we hope that readers consider this Special Issue as an exciting springboard for future research and improved organizational practice. 


\section{Acknowledgements}

Special thanks go to Marie Dasborough for her help in shaping the initial ideas around this Special Issue. We gratefully recognize her contribution in this respect. We also thank the Editor of Human Relations, Paul Edwards, and his professional team, especially Claire Castle, Sarah Hands and Jo Charlton, for outstanding guidance and support throughout the development of this project. Finally, we extend our appreciation to the dedicated efforts of the anonymous reviewers ( 57 in total, some of whom even reviewed two manuscripts!). This Special Issue would not have been possible with their contribution.

\section{Funding}

This work was supported by funding to the second Guest Editor/author from an Australian Research Council Discovery Grant Project ID: DP130102625.

\section{Notes}

1 We see no compelling reason as to why this notion cannot be extended to include emotioninfused concepts too, as the fascination with the positive psychology movement and the concepts that are discussed under its banner suggests (e.g. Salovey et al., 2002).

2 It is interesting to contrast this broader outcome expectation of emotional intelligence with the (unanticipated) effect that it significantly predicts deviant workplace behaviors (see Winkel et al., 2011), though we suggest that this deviance can serve important protective functions for individuals (Lindebaum, 2012).

\section{References}

Alvesson M and Sandberg J (2011) Theory development: Generating research questions through problematization. Academy of Management Review 36(2): 247-271.

Ashforth BE and Humphrey RH (1995) Emotion in the workplace: A reappraisal. Human Relations 48(2): $97-125$.

Ashkanasy NM (2003) Emotions in organizations: A multilevel perspective. In: Dansereau F and Yammarino FJ (eds) Research in Multi-Level Issues. Oxford: Elsevier Science, 9-54.

Ashkanasy NM (2007) Revisiting JOB's mission. Journal of Organizational Behavior 28(4): $353-355$.

Ashkanasy NM (2011) Advancing theory: More than just 'gap filling'. Journal of Organizational Behavior 32(6): 819-821.

Barsade SG and Gibson DE (2007) Why does affect matter in organizations? Academy of Management Perspectives 21(1): 36-59.

Barsade SG, Brief AP and Spataro SE (2003) The affective revolution in organizational behavior: The emergence of a paradigm. In: Greenberg J (ed.) Organizational Behavior: The State of the Science. Mahwah, NJ: Erlbaum, 3-52.

Beal DJ, Trougakos JP, Weiss HM and Green SG (2006) Episodic processes in emotional labor: Perceptions of affective delivery and regulation strategies. The Journal of Applied Psychology 91(5): 1053-1065.

Berkowitz L and Harmon-Jones E (2004) Toward an understanding of the determinants of anger. Emotion 4(2): 107-130.

Diefendorff JM and Greguras GJ (2009) Contextualizing emotional display rules: Examining the roles of targets and discrete emotions in shaping display rule perceptions. Journal of Management 35(4): 880-898. 
Edwards P (2011) Message from the new Editor-in-Chief. Human Relations 65(1): 3-4.

Elfenbein HA (2007) Emotion in organizations: A review and theoretical integration. The Academy of Management Annals 1(1): 315-386.

Figley CR (1995) Compassion fatigue: Toward a new understanding of the costs of caring. In: Stamm BH (ed.) Secondary Traumatic Stress: Self-Care Issues for Clinicians, Researchers, and Educators. Lutherville, MD: Sidran, 3-28.

Fineman S (2004) Getting the measure of emotion - and the cautionary tale of emotional intelligence. Human Relations 57(6): 719-740.

Fineman S (ed.) (2008) The Emotional Organization. Oxford: Blackwell Publishing.

Fisher CD (2010) Happiness at work. International Journal of Management Reviews 12(4): 384-412.

Fisher CD and To ML (2012) Using experience sampling methodology in organizational behavior. Journal of Organizational Behavior 33(7): 865-877.

Fitness J (2008) Fear and loathing in the workplace. In: Ashkanasy NM and Cooper CL (eds) Research Companion to Emotion in Organizations. Cheltenham: Edward Elgar, 61-72.

Foo MD, Elfenbein HA, Tan HH and Aik VC (2004) Emotional intelligence and negotiation: The tension between creating and claiming value. International Journal of Conflict Management 15(4): 411-429.

Fredrickson BL (2003) The value of positive emotions: The emerging science of positive psychology is coming to understand why it's good to feel good. American Scientist 91(4): 330-335.

Frijda N (2007) The Laws of Emotion. Mahwah, NJ: Erlbaum.

Gable SL and Haidt J (2005) What (and why) is positive psychology? Review of General Psychology 9(2): 103-110.

Geddes D and Stickney LT (2011) The trouble with sanctions: Organizational responses to deviant anger displays at work. Human Relations 64(2): 201-230.

Gray HM, Ishii K and Ambady N (2011) Misery loves company: When sadness increases the desire for social connectedness. Personality and Social Psychology Bulletin 37(11): 1438-1448.

Gross J (1998) The emerging field of emotion regulation: An integrative review. Review of General Psychology 2(3): 271-299.

Heinisch DA and Jex SM (1997) Negative affectivity and gender as moderators of the relationship between work-related stressors and depressed mood at work. Work \& Stress 11(1): 46-57.

Hertel J, Schütz A and Lammers C-H (2009) Emotional intelligence and mental disorder. Journal of Clinical Psychology 65(9): 942-954.

Hochschild AR (1983) The Managed Heart: Commercialization of Human Feeling. Berkeley, CA: University of California Press.

Hughes E (1962) Good people and dirty work. Social Problems 10(1): 3-11.

Johns G (2006) The essential impact of context on organizational behavior. Academy of Management Review 31(2): 386-408.

Johnson G and Connelly S (2014) The role of negative emotions in informal failure feedback: The benefits of disappointment and guilt and the detriments of anger. Human Relations, doi 0018726714532856 .

Jordan PJ, Dasborough M, Daus CS and Ashkanasy NM (2010) A call to context. Industrial and Organizational Psychology 3(2): 145-148.

Kanov JM, Maitlis S, Worline MC, Dutton JE, Frost PJ and Lilius JM (2004) Compassion in organizational life. American Behavioral Scientist 47(6): 808-827.

Keltner D and Haidt J (1999) Social functions of emotions at four levels of analysis. Cognition \& Emotion 13(5): 505-521.

Lawrence SA, Troth AC, Jordan JP and Collins AL (2011) A review of emotion regulation and development of a framework for emotion regulation in the workplace. In: Perrewé PL and 
Ganster DC (eds) The Role of Individual Differences in Occupational Stress and Well Being Research in Occupational Stress and Well Being. Bingley: Emerald, 199-266.

Lazarus RS (1999) Stress and Emotion: A New Synthesis. London: Free Association Books.

Lee N, Senior C and Butler M (2012) The domain of organizational cognitive neuroscience: Theoretical and empirical challenges. Journal of Management 38(4): 921-931.

Lindebaum D (2012) I rebel - therefore we exist: Emotional standardization in organizations and the emotionally intelligent individual. Journal of Management Inquiry 21(3): 262-277.

Lindebaum D and Fielden S (2011) 'It's good to be angry': Enacting anger in construction project management to achieve perceived leader effectiveness. Human Relations 64(3): 437-458.

Lindebaum D and Geddes D (2014) In defense of anger: The significance of an under-appreciated moral emotion. Paper presented at the annual meeting of the Academy of Management in Philadelphia, Pennsylvania, 1-5 August.

Lindebaum D and Jordan PJ (2012) Positive emotions, negative emotions, or utility of discrete emotions? Journal of Organizational Behavior 33(7): 1027-1030.

Luthans F, Luthans KW and Luthans BC (2004) Positive psychological capital: Beyond human and social capital. Business Horizons 47(1): 45-50.

McDaniel MA, Rothstein HR and Whetzel DL (2006) Publication bias: A case study of four test vendors. Personnel Psychology 59(4): 927-953.

McKinley W (2007) Special issues as vertical integration: A rejoinder to Priem and Mowday. Journal of Management Inquiry 16(3): 240-245.

Martins A, Ramalho N and Morin E (2010) A comprehensive meta-analysis of the relationship between emotional intelligence and health. Personality and Individual Differences 49(6): $554-564$

Mayer JD and Salovey P (1997) What is emotional intelligence? In: Salovey P and Sluyter DJ (eds) Emotional Development and Emotional Intelligence. New York: Basic Books, 3-31.

Mayer JD, Roberts RD and Barsade SG (2008) Human abilities: Emotional intelligence. Annual Review of Psychology 59: 507-536.

Meadors P and Lamson A (2008) Compassion fatigue and secondary traumatization: Provider self care on intensive care units for children. Journal of Pediatric Health Care 22(1): 24-34.

Mumby DK and Putnam LL (1992) The politics of emotion: A feminist reading of bounded rationality. Academy of Management Review 17(3): 465-486.

Ouweneel E, Le Blanc PM, Schaufeli WB and Van Wijhe CI (2012) Good morning, good day: A diary study on positive emotions, hope, and work engagement. Human Relations 65(9): $1129-1154$.

Oveis C, Horberg EJ and Keltner D (2010) Compassion, pride, and social intuitions of self-other similarity. Journal of Personality and Social Psychology 98(4): 618-630.

Pierce JR and Aguinis H (2013) The too-much-of-a-good-thing effect in management. Journal of Management 39(2): 313-338.

Popper KR (2004) Conjectures and Refutations: The Growth of Scientific Knowledge. London: Routledge.

Priem RL (2006) What happens when special issues just aren't 'special' anymore? Journal of Management Inquiry 15(4): 383-388.

Radcliffe LS and Cassell C (2013) Resolving couples' work-family conflicts: The complexity of decision making and the introduction of a new framework. Human Relations. DOI: $10.1177 / 0018726713506022$.

Salovey P, Mayer JD and Caruso DR (2002) The positive psychology of emotional intelligence. In: Snyder CR and Lopez SJ (eds) Handbook of Positive Psychology. New York: Oxford University Press, 159-171. 
Sell A, Tooby J and Cosmides L (2009) Formidability and the logic of human anger. Proceedings of the National Academy of Sciences 106(35): 15073-15078.

Solomon R (1993) The Passions: Emotions and the Meaning of Life. Indianapolis, IN: Hackett Publishing Company.

Stearns PN and Stearns CZ (1985) Emotionology: Clarifying the history of emotions and emotional standards. The American Historical Review 90: 813-836.

Suddaby R (2010) Editor's comments: Construct clarity in theories of management and organization. Academy of Management Review 35(3): 346-357.

Taris TW and Schreurs PJG (2009) Well-being and organizational performance: An organizational-level test of the happy-productive worker hypothesis. Work \& Stress 23(2): 120-136.

Tiedens LZ (2001) Anger and advancement versus sadness and subjugation: The effect of negative emotion expressions on social status conferral. Journal of Personality and Social Psychology 80(1): 86-94.

Troth AC, Jordan PJ, Lawrence SA and Tse HHM (2012) A multilevel model of emotional skills, communication performance, and task performance in teams. Journal of Organizational Behavior 33(5): 700-722.

Van Kleef GA (2009) How emotions regulate social life: The Emotions as Social Information (EASI) Model. Current Directions in Psychological Science 18(3): 184-188.

Vincent S (2011) The emotional labour process: An essay on the economy of feelings. Human Relations 64(10): 1369-1392.

Waldman DA, Balthazard PA and Peterson SJ (2011) Leadership and neuroscience: Can we revolutionize the way that inspirational leaders are identified and developed? Academy of Management Perspectives 25(1): 60-74.

Weiss HM and Cropanzano R (1996) Affective events theory: A theoretical discussion of the structure, causes and consequences of affective experiences at work. In: Staw BM and Cummings LL (eds) Research in Organizational Behavior: An Annual Series of Analytical Essays and Critical Reviews. Greenwich, CT: JAI Press, Inc., 1-74.

Winkel DE, Wyland RL, Shaffer MA and Clason P (2011) A new perspective on psychological resources: Unanticipated consequences of impulsivity and emotional intelligence. Journal of Occupational and Organizational Psychology 84(1): 78-94.

Xanthopoulou D, Bakker AB and Ilies R (2012) Everyday working life: Explaining within-person fluctuations in employee well-being. Human Relations 65(9): 1051-1069.

Dirk Lindebaum is Reader in Management at University of Liverpool Management School UK. One stream of his research activities pertains to organizational phenomena that involve emotional processes, such as emotional intelligence, leadership, moral emotions and ethics, as well as issues of conformity, power and deviance. Another stream that he has pursued of late concerns the increasing visibility of neuroscientific theories and methods in the study of organizational behavior. [Email: d.lindebaum@liverpool.ac.uk]

Peter J Jordan is Professor of Organizational Behaviour in the Griffith Business School, Griffith University, Australia. He gained his PhD in management at the University of Queensland. He has received significant competitive research funding to examine issues around emotions at work and specifically examining the impact of emotional intelligence at work. His current research incorporates studies looking at physiological measurement of emotions at work and the effects of anger at work. [Email: peter.jordan@griffith.edu.au] 